
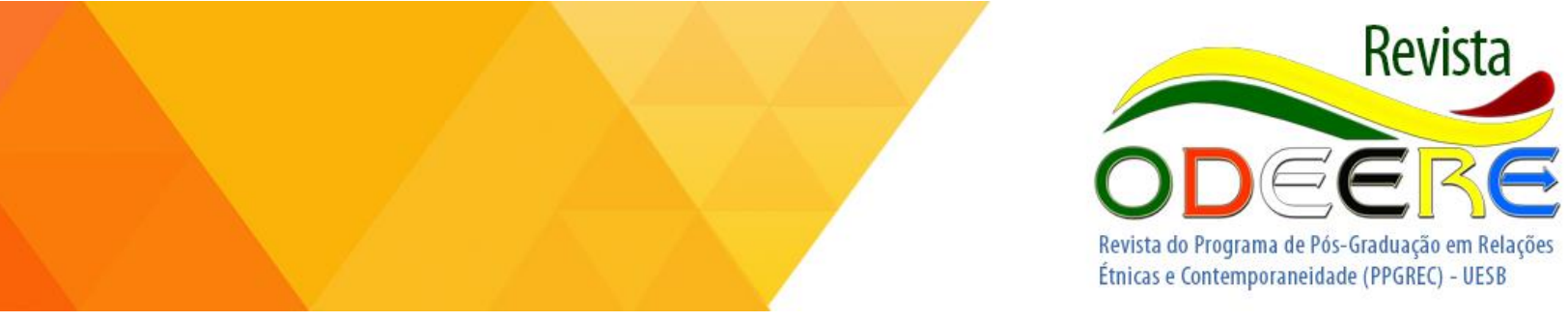

"Retornados ou os restos do Império": um documentário para preservar a memória de Angola

Marilda Monteiro Flores

Universidade Federal do Estado do Rio de Janeiro (UNIRIO) marildasmflores@gmail.com
Resumo: A análise de depoimentos apresentados no documentário "Retornados ou os Restos do Império" permitirá observar as imagens que representam a África presentes na memória daqueles que saíram de Angola após o fim da guerra colonial e posterior independência. $O$ exame de trechos do documentário permitirá refletir sobre as inúmeras possibilidades de análise no trabalho com uma obra fílmica, destacando a relação existente entre a película e o contexto em que foi produzida para a rememoração do evento que trouxe para Portugal milhares de pessoas que fugiam da guerra instalada entre os movimentos de libertação de Angola. 0 documento imagético em questão trabalha com as emoções dos depoentes e se utiliza de imagens que representam o motivo da saída de Angola, apresentando cenas que dialogam com o expectador sobre a memória que possuem do passado recente.

Palavras-chave: Angola, documentário, retornados, memória

Abstract: The analysis of accounts presented in the documentary "Retornados ou os Restos do Império" (Returnees or the Remains of the Empire) will allow us to observe the images which represent Africa in the memory of those who left Angola after the end of the colonial war. The study of snippets from the documentary will allow the reflection on the various analysis possibilities in this study with a cinematic work. It will also highlight the relationship between the film and the context in which it was produced, in order to recall the event which brought to Portugal thousands of people who were running away from the war between the liberation 
movements in Angola. The documentary in question works with interviewees' emotions using images which represent the reason for the exit from Angola and showing scenes that dialog with the spectator about the memory they possess about the recent past.
Keywords: Angola, documentary, returnees, memory

\section{O documentário}

Os Retornados ou os restos do Império, uma produção da Rádio e Televisão de Portugal (RTP) e coprodução Continental Filmes, foi dirigido por Ana Fernandes Costa em 2001. O documentário apresenta depoimentos de antigos colonos portugueses, alguns nascidos em Angola e outros em Moçambique. A película exibe os relatos, misturando imagens da época colonial com imagens alternadas dos entrevistados que falam sobre o êxodo traumático do continente africano. Os testemunhos apontam o episódio de abril de 1974, a Revolução dos Cravos, como o principal motor da descolonização, e revelam uma paixão pelo que deixaram em África. Falam do relacionamento com os portugueses ao chegarem a Lisboa e das dificuldades enfrentadas no início: falta de moradia, desemprego, hábitos, e apontam como um dos principais problemas a falta de identificação com o Estado Português. A principal ênfase dos depoimentos é o retorno forçado para Portugal, uma terra que consideravam estranha.

Nas declarações, é possível verificar a falta de vínculo com a metrópole e o sentimento de perda de Angola, que para alguns é a terra natal. O documentário, baseado no livro de Dulce Cardoso, tem como objetivo principal apresentar as lembranças dos habitantes de Angola (e de Moçambique) sobre os tempos da colônia portuguesa. Em cada depoimento pode ser percebido o pesar pela saída e o sentimento de pertencimento ao continente africano. Enquanto relembram Angola, simultaneamente às falas, o documentário proporciona ao espectador uma identificação com o continente ao apresentar como pano de fundo as imagens da terra e sons de ventos fortes. A voz, do narrador aguça as lembranças de quem viveu o evento, e indica o investimento que o grupo dos que foram chamados de retornados estão implementando para preservar e difundir as imagens guardadas em suas memórias.

O documentário inicia apresentando uma fala que acaba por ser recorrente entre o grupo que se declara exilado em Portugal: "Tenho saudade. Tenho pena. Tenho uma grande paixão por 
Angola"1 ${ }^{1}$. O nome da depoente só aparece quatro minutos depois, Elvira Gomes Faria, mas a expressão do seu rosto, a pausa na fala e a expressão do olhar já são suficientes para o diálogo que a imagem se propõe a travar com o espectador. Ela tem saudade da vida, dos amigos, dos bens, da liberdade, da posição social que deixou em Angola; pena por conta da saída traumática e sem o apoio, que julgava necessário receber, do governo português, e paixão por uma Angola que ainda permanece idealizada em suas lembranças. Lá viveu os melhores anos da sua vida, a juventude. O documentário busca, nesse momento inicial, ser uma representação do sentimento que tem norteado a rememoração de Angola. Se nesse primeiro depoimento o destaque foi para o sentimento de perda com um grande enfoque emocional, no segundo, o depoente apresenta a perda material: "Aos vinte anos quando saí de lá (não informado o local), tinha as minhas t-shirts, meus jeans e meus discos e mais nada. E hoje tenho as minhas recordações"².

Esse detalhe, o da não identificação do local, também é importante, pois apresenta a identificação buscada com a África, não importando a antiga colônia / atual país. O depoente que saiu do território africano aos vinte anos representa milhares de pessoas que, na mesma faixa etária, estavam pisando, pela primeira vez, em Portugal. Muitos, nascidos em solo africano, deixaram para trás uma vida e trouxeram para Portugal elementos importantes para a juventude da década de 1970: camiseta, jeans e discos "e mais nada. São elementos que ajudam a rememorar o ambiente descontraído que não levava em conta o contraste entre o colonizador e o colonizado e faz parte de um discurso construído anos após a saída de Angola. A diferença só foi sentida, de acordo com o discurso de muitos depoentes, a partir do momento em que os movimentos de libertação de Angola começaram a exigir a saída do colonizador e de todos os que tivessem algum vínculo com Portugal, fosse pelo relacionamento profissional, social, pelo nascimento ou pela cor. ${ }^{3}$ O quarto depoimento apresenta um panorama da trajetória vivenciada no êxodo daquele que foi chamado de retornado: "Muitos morreram. Muitos ficaram na miséria, mas muitos ficaram, felizmente, bem. " 4

\footnotetext{
${ }^{1}$ Publicado no Canal da UBICINEMA - https://www.youtube.com/user/ubicinema - último acesso em 11/12/2013

${ }^{2} \mathrm{O}$ nome do segundo do entrevistado não consta, com clareza, no vídeo.

3 Depoimento de Fernando Paisana É importante deixar claro que esse é um discurso dos próprios depoentes, construído, inclusive, a posteriori, ou seja, após a experiência do retorno. Tal discurso reforça a ideia, defendida pelos depoentes, de que eles foram injustamente expulsos de "sua terra".

${ }^{4} \mathrm{O}$ terceiro depoimento destacou Lourenço Marques, atual Maputo, uma cidade de Moçambique que, assim como Angola, experimentou a presença opressora da colonização. Após a independência, a saída dos brancos portugueses ainda é um evento relembrado.
}

Odeere: revista do programa de pós-graduação em Relações Étnicas e Contemporaneidade - UESB. Ano 1, número 1, volume 1, Janeiro - Junho de 2016. 
Durante o início dos combates, em 1961, muitos colonos foram alvo de ataques dos movimentos nacionalistas angolanos. Os mais expressivos na mídia foram: a Revolta da Cassange em janeiro, quando camponeses se revoltaram contra a opressão imposta pela Cotonang; o 04 de fevereiro, quando prisões foram invadidas em Luanda para libertar presos políticos; e o 15 de março de 1961, quando foram atacadas fazendas e casas comerciais de colonos no norte de Angola, resultando no assassinato de brancos e negros e aumentando o número de ações contra a colonização em Angola ${ }^{5}$. Apresentados pela imprensa como expressão da selvageria dos africanos, taxados de terroristas, estes foram movimentos decisivos, tanto para o início da guerra que levou à descolonização, quanto para o início da saída/fuga de colonos de Angola.

A película apresenta a voz do narrador que, misturada com imagens de navios, caixotes no porto, superlotação das embarcações, credita o evento da saída de Angola ao governo ditatorial de Antônio Salazar e Marcelo Caetano. Mas, também, ao "desejo de liberdade dos povos colonizados" que, segundo o narrador, acabou por acelerar a saída dos colonos "a uma velocidade vertiginosa". A fala sobre o ambiente colonial se mistura às imagens de combates, sons de tiros, pessoas correndo pelas ruas e indivíduos, que podem ser identificados com os movimentos de libertação, vistoriando os carros que implementavam uma fuga, pensada como provisória, para países vizinhos.

O clima tenso, apresentado com imagens do arquivo da Rádio e Televisão de Portugal (RTP), mostra, aos dois minutos, a situação de divergência entre os três movimentos de libertação. A voz destaca a instabilidade civil que "conduz o território a um clima de violência incontrolável". Enquanto se ouve a voz do narrador, as imagens do ambiente de guerra nas cidades (de Angola) se cruzam para justificar a sua fala. Como estratégia de legitimação do documento fílmico, o documentário apresenta o testemunho de um militar responsável pelo transporte de milhares de colonos para as terras portuguesas, Antônio Gonçalves Ribeiro, que destacou dois momentos do êxodo: primeiro para o interior e depois para Portugal. Esse e os demais depoimentos dão à película uma marca de realidade, e têm a intenção de fazer com que o espectador se sinta como uma testemunha ocular.

A justificativa para a retirada dos colonos, segundo as imagens apresentadas na película, foi o pedido deles próprios. Aos três minutos, surgem imagens em preto e branco de supostos

\footnotetext{
${ }^{5}$ Para a Revolta da Cassange ver FREUDENTHAL, A. "A Baixa de Cassanje: algodão e revolta”. In: Revista Internacional de Estudos Africanos, Lisboa, n. 18-22, 1995-1999, p. 245-283 e BITTENCOURT, Marcelo, O falar das armas, In: Tese de Doutorado, Programa de Pós-Graduação em História Social da Universidade Federal Fluminense, 1999
}

Odeere: revista do programa de pós-graduação em Relações Étnicas e Contemporaneidade - UESB. Ano 1, número 1, volume 1, Janeiro - Junho de 2016. 
colonos gritando "Queremos ir embora!", seguidas de imagens de pessoas deitadas no chão. A elas mistura-se o depoimento do general, que apresenta todo o esforço que empreendeu para atender aos apelos de colonos. Aos três minutos e quarenta segundos, a voz do narrador apresenta o contraste entre sair de Angola e chegar a Portugal, que para muitos seria "uma metrópole longínqua que desconheciam". E finaliza o trecho da apresentação destacando que aqueles que deixavam Angola "acalentavam a esperança de um rápido regresso".

O documentário acaba por estimular a lembrança, e é o passado que é evocado para construção e seleção do que será lembrado no presente. Mais uma vez, uma mistura de imagens e o discurso do narrador, atrelado aos depoimentos que reconstroem o passado, encerram o primeiro momento de apresentação do documentário. Aos quatro minutos reaparece a primeira depoente, agora com o seu nome na legenda: Elvira Gomes Faria. Se no início da apresentação a sua fala sem identificação representou o sentimento de muitos dos que saíram de Angola, agora é a vez dela, individualmente, justificar o motivo da saída. Em trechos estancados da fala, a edição do documentário destaca frases que explicam a saída: "Mataram meu vizinho à porta. Pensei: Vamos embora, mas voltamos logo. Não levamos nada porque vamos voltar". Enquanto se ouve a voz da depoente, a película apresenta imagens do aeroporto de Luanda e dos trens, que justificam a saída de Angola. Imagens selecionadas e preservadas em um arquivo da RTP para estimular a memória do retorno.

O ato de relembrar atua como um instrumento de seleção sobre o que terá significado no momento da celebração. A lembrança mantém a vida, como destacou Fernando Catroga “Recordo-me, logo existo" ${ }^{6}$ - pois mesmo manipulada social e politicamente, a lembrança do êxodo, que tem a sua origem no passado recente, acaba por ser um momento de celebração. Celebra o passado para afirmar quem são os que lembram no presente, pois será através das rememorações que estes construirão as suas identidades. Portanto, quando o documentário usa o artifício de reavivar as lembranças do passado, através do diálogo entre a imagem e a fala dos depoentes, esse exercício dá ao espectador a sensação de participar, mesmo que por tabela, do evento. Essa celebração é o que Catroga chama de metamemória:

Percebe-se agora melhor por que é que a comemoração constitui uma metamemória inscrita na memória-repetição, pois é inseparável das suas ritualizações. A intriga que nelas se conta - mormente quando se organiza como

\footnotetext{
${ }^{6}$ CATROGA, Fernando. -A representificação do ausente. In: Os passos do homem como restolho do tempo - memória e fim do fim da História. Coimbra: Almedina, 2009, p.120
}

Odeere: revista do programa de pós-graduação em Relações Étnicas e Contemporaneidade - UESB. Ano 1, número 1, volume 1, Janeiro - Junho de 2016. 
calendário cívico - dialecticiza a presença da ausência através de uma "cenografia" em que se "teatrializa" e "esteticiza" o narrado. ${ }^{7}$

A construção fílmica utiliza essas estratégias para reafirmar a mensagem que passa por meio do uso das imagens e sons, seja de falas com diferentes entonações ou mesmo de uma música que apoia a fala do narrador. Essa memória-repetição, recurso utilizado no documentário, acaba por direcionar ou estimular o espectador à causa do depoente.

\section{Preservando imagens para rememorar}

Rememorar é uma habilidade desenvolvida com o objetivo de preservar as lembranças, as culturas e, mais ainda, de conservar ou construir uma identidade que seja um marco diferenciador em relação ao outro. Com isso, o discurso afinado acaba por ser mais um elemento para compor a identidade do grupo que se diferenciou dos portugueses no momento da chegada a Lisboa, mas que também já se distinguia no período em que habitava em Angola. Para Stuart Hall essas identidades

[...] emergem no interior do jogo de modalidades específicas de poder e são, assim, mais produto da marcação da diferença e da exclusão do que o signo de uma unidade idêntica, naturalmente constituída, de uma "identidade" em seu significado tradicional - isto é, uma mesmidade que tudo inclui, uma identidade sem costuras, sem diferenciação interna. ${ }^{8}$

Portanto, aqueles que chegaram a Portugal após a guerra iniciada em 1961, mais os que chegaram após a independência de Angola, experimentaram, durante os treze anos de guerra, a incerteza referente ao futuro que os esperava. Desde a chegada a Portugal, o vocabulário recheado de expressões africanas, os gestos e hábitos com maior desenvoltura e a liberdade de ir e vir sem muitos limites que haviam desfrutado no passado acabaram por gerar uma distinção e uma busca de preservação da memória, que foram manifestadas nos nomes que lembravam a África em pequenos estabelecimentos comerciais por eles criados, na escolha de músicas e filmes que devam a oportunidade de rememorar, e em outras inúmeras ocasiões.

Como os encontros de antigos colonos e a edição de livros comemorativos, a produção fílmica foi fundamental para a reafirmação de uma identidade angolana que se estabeleceu em solo português e que, provavelmente, se modificou ao longo das quatro décadas que separam a experiência do retorno à sua rememoração atual. De todo modo, o uso de imagens dá ao

\footnotetext{
${ }^{7}$ Idem

${ }^{8}$ HALL, Stuart. Quem precisa da identidade? In: SILVA, Tomaz Tadeu (org. e trad.). Identidade e diferença: a perspectiva dos estudos culturais. Petrópolis: Vozes, 2000. p. 109
}

Odeere: revista do programa de pós-graduação em Relações Étnicas e Contemporaneidade - UESB. Ano 1, número 1, volume 1, Janeiro - Junho de 2016. 
espectador a possibilidade de se sentir, mesmo que a certa distância, uma testemunha ocular do evento. Esse elemento motivador incentivou que no início do século XXI um número maior de produções chegasse ao mercado cultural para compartilhar e vivenciar a saga vivida por todos aqueles que chegaram a Portugal, fugindo da guerra colonial em Angola.

O material fílmico, produzido para as rememorações da chegada a Portugal, permite observar os elementos que vinculam a construção da identidade que oscila entre ser angolana ou de descendentes de portugueses. O estilo escolhido visa dar uma representação da realidade que antigos colonos e descendentes vivenciaram no evento do êxodo angolano. Logo, a produção de um documento imagético acaba por induzir o espectador a perceber um caráter de autenticidade nas narrativas mescladas às imagens de arquivo jornalístico que, aos poucos, são inseridas no documento.

Essa característica do documentário obscurece o aspecto ficcional do gênero e se propõe a iniciar um diálogo entre a realidade apresentada na película e o espectador, pois estes filmes são produzidos para servirem de testemunhos do passado. Mas, se a obra fílmica é uma construção ficcional, como ela pode ser usada para reafirmar eventos e como o seu uso pode ser apropriado para a consolidação do discurso?

Analisar as imagens de modo a refletir sobre as intenções da produção permitirá considerar a influência dos discursos proferidos pelos depoentes do documentário. Em Os Retornados ou os restos do Império, os discursos vão, aos poucos, apresentando as trajetórias dos antigos moradores de Angola, culminando com o processo de descolonização africana. Para Manuela Penafria, "Analisar um filme é sinónimo de decompor esse mesmo filme". ${ }^{9}$ Portanto, não é somente uma tentativa de estabelecer uma representação do que o projeto fílmico apresenta. Trata-se de um exercício de decompor o documento quadro a quadro, que tem como objetivo entender as relações que envolvem a produção e organizar uma descrição, com o maior número de detalhes possíveis, da imagem, além de propor explicações para as articulações entre o contexto de produção, a organização do roteiro, a escolha da direção, o elenco e o contexto histórico inserido. Para Penafria, a análise de um material que se apresenta como um documento envolve:

[...] acima de tudo, uma actividade que separa, que desune elementos. E após a identificação desses elementos é necessário perceber a articulação entre os

\footnotetext{
${ }^{9}$ PENAFRIA, Manuela, Análise de Filmes - conceitos e metodologia(s). Artigo apresentado no VI Congresso SOPCOM, abril de 2009, p. 2
}

Odeere: revista do programa de pós-graduação em Relações Étnicas e Contemporaneidade - UESB. Ano 1, número 1, volume 1, Janeiro - Junho de 2016. 
mesmos. Trata-se de fazer uma reconstrução para perceber de que modo esses elementos foram associados num determinado filme. ${ }^{10}$

Para Cristiane Nova, um filme pode se relacionar com a História como documento, uma vez que é um vestígio do passado, remoto ou não. Filmes são testemunhos das sociedades que os produziram. ${ }^{11}$ Logo, a produção imagética sobre um evento constitui arquivo importante e reflete o seu tempo e o cinema acaba por se transformar em uma espécie de arquivo vivo sobre o tempo passado logo, a produção imagética tem uma função importante para o historiador.

Os depoimentos e as imagens que representam a África apresentadas no documentário Retornados ou os Restos do Império permitem comparar e refletir sobre as inúmeras possibilidades de trabalho com uma obra fílmica e, ainda, perceber a relação existente entre a película e o contexto em que foram produzidas as rememorações do evento do retorno. $\mathrm{O}$ filme trabalha com as emoções dos depoentes e se utiliza das imagens que representam a Angola de seus sonhos, para transmitir ideias ou para reafirmar o sentimento da falta que sentem da terra natal. A obra fílmica permite e incentiva a rememoração, pois possuindo uma imensa capacidade de criar e recriar cenas do passado, dialoga com o espectador, que pode ser testemunha de um tempo ou evento que o documento fílmico apresenta na tela. Para Rosenstone, o recurso do filme é a possibilidade de criar e recriar momentos que fazem ou fizeram parte do cotidiano de uma sociedade para serem apresentados às outras gerações e possibilitando a revisão de questões que podem estar obscurecidas. ${ }^{12}$

Logo, vale perceber as estratégias empreendidas pelos que retornaram de Angola na utilização de imagens sobre o período da descolonização e posterior saída rumo a Portugal. As ruas das cidades, as cores contrastantes da vegetação e da terra vermelha, as conversas nos bares, a cerveja Cuca, os cinemas nos fins das tardes de sábado, os amigos, e tantas outras recordações, são instrumentos que preservam uma Angola que só existe em suas memórias. E são as lembranças, organizadas a partir do livro de uma retornada, que o documentarista vai explorando ao longo do tempo da película. ${ }^{13}$

\footnotetext{
${ }^{10}$ Idem p. 2 e 3

${ }^{11}$ NOVA, Cristiane. O cinema e o conhecimento da história. Olho da História: revista de história contemporânea. Salvador, UFBA, v. 2, n.3. p. 218-233, 1996.

${ }^{12}$ ROSENTSTONE, Robert. A História nos filmes, os filmes na história. São Paulo: Paz e Terra, 2010, p.35.

${ }^{13}$ O documentário, foi produzido a partir da obra de uma retornada, Dulce Maria Cardoso. O livro O Retorno, publicado em 2011 pela editora Tinta da China, Lisboa
}

Odeere: revista do programa de pós-graduação em Relações Étnicas e Contemporaneidade - UESB. Ano 1, número 1, volume 1, Janeiro - Junho de 2016. 
Como vimos, no primeiro depoimento do documentário em análise, a frase inicial expressa o sentimento do grupo em relação à terra que está distante: "Tenho saudade. Tenho pena. Tenho uma grande paixão por Angola" ${ }^{14}$. Observar o documentário permite aproximar e conhecer um pouco mais o tema proposto através das lentes daqueles que o produziram e perceber o embate constante que travam com a sociedade em que vivem - a portuguesa. Porém, qual a função destas obras para a construção da identidade do grupo?

A Angola "descontraída, próspera e bela" não era somente mais uma terra, mas representava, também, a possibilidade de liberdade sem o controle exacerbado do Estado Salazarista. Para os colonos nascer, crescer ou viver em Angola não era só um sonho, mas a experiência de estar em um dos locais mais prósperos e livres do Império. Além disso, estar na colônia significava usufruir de uma prerrogativa fundamental, pois ser branco, por si mesmo, era ser reconhecido como civilizado. Independentemente da condição social alcançada na colônia pois é sabido que existiram colonos pobres, - era garantido aos brancos que eles não estariam na base da pirâmide social, pois este lugar, sem sombra de dúvida, era reservado a africanos. Por tudo isso, nos relatos apresentados no documentário, o sentimento latente é que Angola é, ainda, para a maioria dos entrevistados, um local para onde pretendem regressar, e é nela que pensam quando ouvem a palavra "retorno".

O sentimento de pertencimento ou de propriedade de territórios no continente africano é apresentado aos quarenta e dois segundos do vídeo: "retornado, adj. e s.m. que ou aquele que, após a proclamação da independência dos territórios portugueses da África, regressou a Portugal. In dicionário da Língua Portuguesa. 7ạ edição, Porto Editora" ${ }^{15}$ O silêncio continua em fundo preto até os cinquenta segundos, quando imagens do aeroporto em Nova Lisboa apresentam imensas filas de desembarque e um amontoado de caixas. Então, a voz do narrador apresenta aos espectadores aquele que foi considerado um dos principais motivos do regresso para Portugal:

O regime ditatorial português de Salazar a Caetano é derrubado em 25 de abril de 1974. A Guerra Colonial mantida pelo salazarismo contra os movimentos de libertação nas Províncias Ultramarinas Portuguesas em África, que durava há treze anos, chega ao fim. (Narrador 0:53-1:12min.)

Enquanto se ouve a voz do narrador, no vídeo são apresentadas imagens de grandes engarrafamentos nas estradas de Luanda. Automóveis sendo embarcados em navios cargueiros e

\footnotetext{
${ }^{14}$ Publicado no Canal da UBICINEMA - https://www.youtube.com/user/ubicinema - último acesso em 11/12/2013.

${ }^{15}$ Abertura do documentário. Escrito em fundo preto com letras brancas e sem som.
} 
imensas filas de carros sendo abandonados nas estradas. A voz do narrador misturada às malas e caixotes se cala diante da cena de uma mulher que, vencida pelo cansaço, dorme no chão com os dedos entrelaçados, próximos à boca, como se estivesse fazendo uma prece enquanto dorme. Imagens e narração se misturam e apresentam ao espectador a oportunidade de reviver um acontecimento. Se ver numa cena? Sentir novamente o medo da guerra? Relembrar um passado próximo? Não deixar que o esquecimento impere?

Um documentário pode suscitar sensações no espectador e também não deixar que uma lembrança seja silenciada pelo esquecimento. Na obra de Ruy Duarte de Carvalho, $A$ câmara, $a$ escrita e a coisa dita ${ }^{16}$, o autor apresenta um resumo das atividades realizadas ao longo da sua produção como cineasta e discute a fabricação de identidades e como as diferenças entre colonos e africanos eram acentuadas nas ex-colônias. O autor revela, ainda, a importância do cinema como um grande auxiliador do governo português, que se utilizava das imagens para doutrinar e reafirmar conceitos. Era o cinema que fazia a propaganda para o Estado e, ainda, incentivava a ida

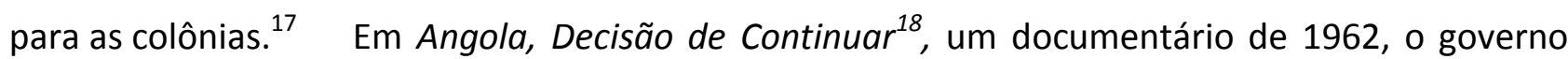
misturou imagens dos massacres ocorridos no norte do país e da intervenção do exército, tudo regado com discursos de Salazar incentivando a população a defender Angola contra o "inimigo estrangeiro". ${ }^{19}$

No período salazarista, o formato de documentário dava à produção a legitimidade necessária para apresentar ao mundo a ideia de boa relação entre colonos e colonizados, destacando as benesses portuguesas para o povo ou o legado de povo civilizador. Desde então, as produções, muitas vezes recicladas, além de destacar a importância dos portugueses em solo africano, apresentavam imagens de um progresso vertiginoso da economia angolana. O documentarismo de propaganda era usado tanto para atrair novos colonos quanto para incentivar a permanência em África no ambiente que se instalou após o início da guerra colonial. Para Maria do Carmo Piçarra, esses documentários foram produzidos para servirem ao governo e, ainda, no contexto de disputas entre as nações, apresentar a ideia de que Portugal possuía uma administração diferente em. Portanto, naquele momento, o uso de imagens

\footnotetext{
${ }^{16}$ CARVALHO, Ruy Duarte de. A câmara, a escrita e a coisa dita... fitas, textos e palestras. Lisboa: Cotovia, 2008.

${ }^{17}$ A Agência Geral das Colônias (AGC), criada em 1924, possuía o objetivo de informar e divulgar as notícias sobre as colônias.

${ }^{18}$ Coprodução da RTP, texto de Horácio Caio e coordenação e montagem de Vasco Hogan Teves.

${ }^{19}$ Note-se que as ações são explicadas por Salazar como resultantes das manipulações e dos interesses do comunismo internacional em Angola.
}

Odeere: revista do programa de pós-graduação em Relações Étnicas e Contemporaneidade - UESB. Ano 1, número 1, volume 1, Janeiro - Junho de 2016. 
[...] visam mostrar que a situação na colônia está controlada, que esta é um destino atraente para a imigração e que a política colonial da ditadura está a ser bem-sucedida. Além do mais, as empresas de referência em termos de actividades económicas precisam de filmes de propaganda que criem um novo mercado, ainda em potência, para as produtoras de filmes. ${ }^{20}$

Portanto, a produção fílmica com intenções políticas e identitárias não é uma novidade para aqueles que fazem uso das imagens no tempo presente, pois isso já fazia parte do cotidiano do antigo colono português. Se ele foi atraído por uma mensagem imagética, agora faz uso dela para representar e relembrar o lugar para o qual foi atraído. O documentário, então, acaba por ser estratégico para a rememoração, pois faz uso dos recursos do cinema, como roteiro, iluminação, edição, dentre outros, e procura um diferencial, que é a relação mais direta com o espectador ao apresentar imagens de arquivo que trazem à memória momentos vividos no passado, aproximando-o de uma realidade representada nas telas. Diferente dos filmes de ficção, em que os atores são dirigidos, no documentário o diretor "não dirige actores, não constrói personagens", ${ }^{21}$ tudo cria uma noção de realidade, pois as pessoas apresentadas fazem parte da realidade passada, não são atores profissionais que representam um papel, são testemunhos, e esse artifício é mais um elemento que dá credibilidade ao sujeito que fala.

Logo, as memórias que evocam e são apresentadas com os recursos do cinema chegam ao expectador como mais um documento sobre o passado que deixaram em África. A Angola apresentada é a dos sonhos, a que vivia isolada dos acontecimentos da Metrópole. Portanto, transmite-se a ideia de que Lisboa só passou a ter significado na hora do retorno. O documento fílmico explora a ideia de que "Expulsos do paraíso por pecados originais não assumidos, eles [os retornados passaram a viver pela memória"22. A Angola deixada na juventude não existe mais. Relembrá-la parece uma forma de resgate de um tempo que passou.

Os depoimentos daqueles que foram chamados de retornados iniciam o documentário com uma tonalidade grave, uma voz pesada, dando uma ideia de sofrimento. Em seguida, são misturadas imagens dos tempos coloniais, destacando o caráter quase que messiânico do colonizador. Não se fala em dificuldades de convívio entre colonos e colonizados. Não se fala em opressão física ou psicológica, da supressão de direitos, nem da forma como as atividades laborais

\footnotetext{
${ }^{20}$ PIÇARRA, Maria do Carmo. Cinema Império: o "fado tropical" na propaganda., In: Angola o nascimento de uma nação. Lisboa: Guerra e Paz, 2013, p. 48.

${ }^{21}$ PENAFRIA, Manuela. O ponto de vista no filme documentário. Covilhã: Universidade da Beira do Interior, 2001, p 2

22 DACOSTA, Fernando, Os Retornados mudaram Portugal. Lisboa: Parsifal, 2013, p. 61
} 
eram organizadas. O outro é quase invisível na película, só aparecendo como pano de fundo, trabalhando nas plantações, realizando serviços ou quando pega em armas e se revolta contra o domínio português. A voz evocada é a de um passado que foi recheado de expectativas e que se organiza no presente através de um aglomerado de memórias.

Mesmo que seja uma representação do passado e tenha um discurso sobre o mesmo, o documentário apresenta um ponto de vista atual sobre um objeto pretérito. Um filme, mesmo que trabalhe com um tema real, não "abandonará a sua condição de representação e, portanto, de algo que, no máximo, apenas representa o real e que não coincide com este"23. Mas quando se faz a opção por um documentário, a primeira motivação é a busca por um fato real e a utilização de recursos que façam uma ponte entre a imagem transmitida e o espectador. Portanto o trabalho da edição busca a construção de um tema através da mistura imagens do passado com imagens do presente e, simultaneamente a exibição das imagens, a voz do narrador faz uma ponte entre as imagens apresentadas e o espectador. ${ }^{24}$

\section{Considerações finais}

O uso das palavras misturadas às imagens funciona para explicar o evento ou a angústia que os depoentes sentem após a saída de Angola. Ao apresentar a questão do esvaziamento da identidade, o documentário resume a questão de forma mais objetiva e expressa, através das imagens intercaladas com os depoimentos, fazendo uma síntese do que representou o êxodo.

São momentos sonorizados que recriam sensações, hesitações, medo, e permitem ao espectador a interpretação, quase que orientada, daquilo que está assistindo. Angola está sendo apresentada como a terra natal, a terra dos sonhos, um mundo encantado que foi estancado. Não se discute o relacionamento com os povos que estavam sob o domínio colonizador, nem com aqueles que, para sobreviver, foram se assimilando aos costumes trazidos da Europa. A Angola, presente em suas recordações é a "Terra Prometida", local de lembranças, sonhos, expectativas e de formação das suas identidades.

Logo, o ambiente retratado nos documentos imagéticos construídos para rememorar um evento possui objetivos específicos, pois trata-se de obras que "têm a clara intenção de recriar o

\footnotetext{
${ }^{23}$ NOVA, Cristiane. O cinema e o conhecimento da história. In: Olho da História: revista de história contemporânea, Salvador: UFBA, v. 2, n.3. p. 218-233, 1996

${ }^{24}$ Idem
}

Odeere: revista do programa de pós-graduação em Relações Étnicas e Contemporaneidade - UESB. Ano 1, número 1, volume 1, Janeiro - Junho de 2016. 
passado e são reconstruções para dar mais significado ao evento". ${ }^{25} \mathrm{O}$ documentário em questão reconstrói um material para dar sentido de autenticidade. As palavras, os gestos, as pausas na fala, a respiração que pesa, são formas de dialogar com o espectador para convencê-lo de um pensamento ou dos embates que envolvem o tema em questão.

Fernando Catroga ao discutir a questão da memória destacou que aquele que sobrevive a um trauma, o seu testemunho acaba por ganhar uma função de representação da verdade, pois as suas recordações são apresentadas como uma espécie de memória viva. ${ }^{26}$ Logo os depoimentos, atrelados ao recurso da imagem, foram selecionados e apresentados ao público como uma espécie de documento sobre o passado e caberá ao historiador, ao analisá-lo, levar em consideração as armadilhas construídas pelo discurso memorialista. Os testemunhos apresentados no documentário, apresentam os retornados como um grupo que se organiza no presente e que utilizam as imagens que representam o passado como uma maneira de identificação ${ }^{27}$.

\section{Bibliografia}

CARDOSO, Dulce Maria, O Retorno, Rio de Janeiro, Tinta da China, 2012

CARVALHO, Ruy Duarte de. A câmara, a escrita e a coisa dita... fitas, textos e palestras. Lisboa: Cotovia, 2008.

CASTELO, Cláudia, O modo português de estar no mundo. O luso-tropicalismo e a ideologia colonial portuguesa (1933-1961), In O Mundo Continuará a Girar. Prémio Victor de Sá de História Contemporânea, 20 anos (1992-2011), Organização: Henrique Barreto Nunes, José Viriato Capela, Braga, 2011

CATROGA, Fernando. A representificação do ausente. In: Os passos do homem como restolho do tempo - memória e fim do fim da História. Coimbra: Almedina, 2009.

DACOSTA, Fernando. Os Retornados mudaram Portugal. Lisboa: Parsifal, 2013.

HALL, Stuart. Quem precisa da identidade? In: SILVA, Tomaz Tadeu (org. e trad.). Identidade e diferença: a perspectiva dos estudos culturais. Petrópolis: Vozes, 2000. p. 103-133.

\footnotetext{
${ }^{25}$ ROSENTSTONE, Robert. A História nos filmes, os filmes na história. São Paulo: Paz e Terra, 2010.

${ }^{26}$ CATROGA, Fernando. -A representificação do ausente. In: Os passos do homem como restolho do tempo - memória e fim do fim da História. Coimbra: Almedina, 2009, p.42

${ }^{27}$ HALBWACHS, Maurice. A memória coletiva. São Paulo: Vértice, 1990. Pág. 60
} 
HALBWACHS, Maurice. A memória coletiva. São Paulo: Vértice, 1990

NOVA, Cristiane. O cinema e o conhecimento da história. Olho da História: revista de história contemporânea. Salvador, UFBA, v. 2, n.3. p. 218-233, 1996.

PENAFRIA, Manuela, Análise de Filmes - conceitos e metodologia(s). Apresentado no VI Congresso SOPCOM, abril de 2009.

PENAFRIA, Manuela. O ponto de vista no filme documentário. Covilhã: Universidade da Beira do Interior, 2001.

PIÇARRA, Maria do Carmo. Cinema Império: o "fado tropical" na propaganda. In: Angola o nascimento de uma nação. Lisboa: Guerra e Paz, 2013.

ROSENTSTONE, Robert. A História nos filmes, os filmes na história. São Paulo: Paz e Terra, 2010.

Marilda dos Santos Monteiro das Flores: Possui graduação em Licenciatura em História pela Universidade do Estado do Rio de Janeiro (2002) e mestrado em Curso de Mestrado e Doutorado da UERJ pela Universidade do Estado do Rio de Janeiro (2008); Doutoranda em História Social pela Universidade Federal do Estado do Rio de Janeiro - UNIRIO (2014). É professora regente da rede estadual do Estado do Rio de Janeiro. Atuando principalmente nos seguintes temas: lei 10.639/2003, ensino de história, memória e identidade, Descolonização e Retornados de Angola.

Artigo recebido para publicação em: Março de 2016.

Artigo aprovado para publicação em: Maio de 2016. 